J. Dairy Sci. 99:9925-9930

http://dx.doi.org/10.3168/jds.2015-10770

(C) American Dairy Science Association ${ }^{\circledR}, 2016$.

\title{
Technical note: Preliminary evaluation of an automated indwelling rumen temperature bolus measurement system to detect pyrexia in preweaned dairy calves
}

\author{
W. A. Knauer, ${ }^{* 1}$ S. M. Godden, ${ }^{*}$ and N. McDonald $\dagger$ \\ *Department of Veterinary Population Medicine, and \\ †Department of Animal Science, University of Minnesota, St. Paul 55108
}

\begin{abstract}
Indwelling rumen temperature bolus (RTB) systems have the potential to offer a convenient and timely method of detecting pyrexia, indicative of active infectious disease. The aim of this pilot study was to evaluate the utility of using RTB systems in preweaned dairy calves. First, an in vitro study was performed to evaluate the accuracy of the RTB in its immediate environment. Thirteen RTB were immersed in a hot water bath (WB). Variably collected RTB temperatures were then matched to WB temperatures, which varied from 36 to $41^{\circ} \mathrm{C}$, with $1 \mathrm{~h}$ spent at each temperature. Second, an in vivo study was performed to evaluate the ability of the RTB to predict a rectal thermometer (RT) temperature. Ten healthy heifer calves less than 1 wk of age were administered an RTB. Rectal thermometer and matched RTB temperatures were taken hourly, over a 6 -h period, 1 day per week during wk $1,3,5$, 7 , and 9 of age. During each 6 -h observation period, calves were offered both water and milk feedings and temperatures recorded every $15 \mathrm{~min}$ for $1 \mathrm{~h}$ thereafter. For both studies, the relationship between RTB and one of WB (in vitro) or RT temperature (in vivo) was described by calculating a concordance correlation coefficient (CCC) and by use of a multivariable linear regression model with repeated measures. For the in vivo study, the model also controlled for week and breed. Diagnostic test characteristics were calculated for the ability of individual RTB measures to detect pyrexia $\left(\mathrm{RT} \geq 39.5^{\circ} \mathrm{C}\right)$. For the in vitro study, the association between the RTB and a known temperature was strong $(\mathrm{CCC}=0.95)$, but the RTB measures underestimated the temperature of the water bath by $0.43 \pm 0.08^{\circ} \mathrm{C}$. For the in vivo study, the association between RT and
\end{abstract}

Received December 15, 2015.

Accepted August 22, 2016.

${ }^{1}$ Corresponding author: knaue020@umn.edu the RTB temperature measurement in a calf was weaker $(\mathrm{CCC}=0.29)$; the average RTB temperature was 0.33 $\pm 0.06^{\circ} \mathrm{C}$ lower than the RT temperature. The sensitivity $(29 \%)$ and positive predictive value $(17 \%)$ of using individual RTB measures to detect a fever was low. The results of this pilot study suggest that an individual RTB measurement may not be a good diagnostic test to detect pyrexia in calves.

Key words: dairy calf, temperature, rumen temperature bolus

\section{Technical Note}

Early detection and treatment of calfhood diseases (e.g., scours, pneumonia) should result in a better short- and long-term outcome for the animal (McGuirk, 2008). Therefore, systems or management tools that can aid in early detection (and treatment) of calfhood disease are of interest to producers and veterinarians for animal well-being and the sustainability of the dairy enterprise. Rectal temperature is one of the most commonly used and most useful indicators of the relationship between a dairy calf, her disease status (e.g., diarrhea, pneumonia), and her physical environment (Liang et al., 2013), although daily screening of rectal temperatures in dairy calves is labor intensive and, thus, not routinely performed on dairies.

Rumen temperature bolus (RTB) systems, which use an indwelling temperature-sensing device to automatically monitor individual animal rumen temperature over time, have the potential to facilitate a more timely detection of some disease states. Rumen temperature bolus systems are available commercially for use in adult cattle and are newly available, but not yet validated, for use in calves. The Bella Ag Cattle Temperature System (Bella Ag LLC, Loveland, CO) consists of the bolus, a data collector (antenna), and a software monitoring system. The calf bolus is $7 \times 3$ $\mathrm{cm}$, weighs $45 \mathrm{~g}$, and contains a magnet, a battery, a temperature-sensing device, and a data transmitter in a silicone base. It is orally administered soon after birth, 
sits in the reticulorumen of the calf and has a reported precision of $\pm 0.05^{\circ} \mathrm{C}$ between 32.2 to $43.3^{\circ} \mathrm{C}$ and an accuracy of $\pm 0.25^{\circ} \mathrm{C}$. The bolus automatically takes reticuloruminal temperatures and variably transmits these temperatures to a software monitoring program. Current software algorithms alert the user when the rumen temperature fluctuates by $1.1^{\circ} \mathrm{C}$ above or below the average bolus reading for the calf. Though validation has been completed for various automated body temperature-sensing systems, including rumen boluses, in adult dairy cows (Bewley et al., 2008a; Rose-Dye et al., 2011; Tismet et al., 2011), little is known about the accuracy and potential utility of using an RTB system to aid producers in detecting morbidity in preweaned dairy calves.

To address this question, our first objective was to describe the ability of the Bella Ag calf RTB system to accurately measure the temperature of its immediate environment, when placed in a water bath (WB). We hypothesized that the RTB measures would be within $\pm 0.25^{\circ} \mathrm{C}$ of the WB temperature. A difference of $0.25^{\circ} \mathrm{C}$ was chosen for both the in vitro and in vivo studies because it is considered by the authors to be both biologically and clinically important and is within the company-reported accuracy of the bolus. This study began with an in vitro phase where 13 RTB were placed on a metal rack and completely submerged in a water bath (Blue M Magni-Whirl, Blue M Electric Company, Blue Island, IL). The water bath contained $8 \mathrm{~L}$ of tap water, was continually agitated, and was heated to $36^{\circ} \mathrm{C}$ and maintained at this temperature for $1 \mathrm{~h}$. Every hour, the WB temperature was increased by $1^{\circ} \mathrm{C}$, covering a biologically important range from 36 to $41^{\circ} \mathrm{C}$ (Smith, 2009). The temperature of the water was measured and recorded every 5 min using a liquid-inglass thermometer (Fisher brand $76 \mathrm{~mm}$ Immersion, Fisher Scientific, Pittsburgh, PA) with a resolution of $1^{\circ} \mathrm{C}$ and an accuracy of $\pm 0.5^{\circ} \mathrm{C}$. We expected each RTB to variably transmit a temperature measure to the computer software at least every $15 \mathrm{~min}$. The RTB readings that occurred in the $15 \mathrm{~min}$ after increasing the water bath temperature by $1^{\circ} \mathrm{C}$ were removed from analysis to account for potential bolus temperature lag as described by Vickers et al. (2010). Time-stamped RTB temperature measures were downloaded from computer software and each WB temperature reading was then matched to RTB readings that were within $\pm 2.5 \mathrm{~min}$.

Our second objective was to describe the relationship between rectal thermometer (RT) and RTB temperature measures in growing dairy calves from 1 wk of age to $3 \mathrm{wk}$ postweaning. Secondary objectives were to describe whether the relationship between rectal tem- perature and RTB measurements changed significantly with other factors, including the ingestion of water or milk meals, and to determine the test characteristics of the RTB to detect pyrexia when pyrexia was defined as a rectal temperature $\geq 39.5^{\circ} \mathrm{C}$ (referent test). We hypothesized that the RTB measurement would be within $\pm 0.25^{\circ} \mathrm{C}$ of the $\mathrm{RT}$ measurement, regardless of calf age, that ingestion of water or milk would not significantly change this relationship, and that RTB measures would accurately detect naturally occurring pyrexia in preweaned calves.

The in vivo study was conducted at the University of Minnesota Saint Paul Teaching Dairy, St. Paul, MN, from October 24, 2014, to January 16, 2015. The use of animals in this study was approved by the University of Minnesota Institutional Animal Care and Use Committee \#1409-31832A. Ten female Holstein or Crossbred $($ Holstein $\times$ Jersey $\times$ Swedish Red) calves less than 1 wk in age were examined by a licensed veterinarian and were enrolled if they were healthy. Eligible calves were orally administered a lubricated (KY Jelly, Johnson \& Johnson, Markham, ON, Canada) Bella Ag calf RTB by the study technician at the time of enrollment. The bolus and calf identification numbers were recorded in the Bella Ag Temperature Monitoring Software (Bella Ag Cattle Temperature System, Bella Ag LLC). Data collection for study calves occurred on $1 \mathrm{~d}$ every $2 \mathrm{wk}$ (during wk 1, 3, 5, 7, 9 and 11 of age). On each datacollection day, calves were moved from their outside hutches at $1100 \mathrm{~h}$, weighed with an electronic scale, and brought to an indoor study area with the Bella $\mathrm{Ag}$ antenna mounted in the room. Calves were observed for $6 \mathrm{~h}$, from 1200 to $1800 \mathrm{~h}$. During this time, calf rumen temperature was variably transmitted to Bella Ag software and rectal temperatures were collected in duplicate using a digital thermometer (Medline Industries Inc., Mundelein, IL; accuracy: $\pm 0.1^{\circ} \mathrm{C}$ ) once per hour. Calves were offered $2 \mathrm{~L}$ of room temperature (average $=24^{\circ} \mathrm{C}$ ) water at $1400 \mathrm{~h}$, and the evening milk feeding (average $=38.1^{\circ} \mathrm{C}$ ) was offered at $1600 \mathrm{~h}$. Time of feeding, milk or water temperature, and amount consumed was recorded. Rectal temperatures were taken immediately before the milk or water meal and at approximately 15-min intervals over the next hour. Average ambient temperature within the barn was recorded. After each data-collection day, automatically captured time-stamped RTB temperature measurements were downloaded from farm computer Bella Ag software and manually matched to RT measurements that were collected within $\pm 10 \mathrm{~min}$ of each other.

Data analyses for both studies were performed in SAS (ver. 9.3, SAS Institute, Cary, NC) except where noted. In vitro analysis included descriptive statistics to 
describe (mean, SD, range) WB and RTB temperature and to check for normality and outliers. A Pearson correlation coefficient and a concordance correlation coefficient (CCC) were calculated to describe the correlation between WB temperature and RTB temperature measurement, plus a CCC plot was generated (STATA ver. 14, Statcorp, College Station, TX). The difference between WB and RTB temperature was described using a mixed linear model that explained the difference in temperature by device (WB or RTB). The random effect of experimental day and repeated measures for each bolus were accounted for in the model. Final significance was determined at $P<0.05$.

For the in vivo portion of the analysis, descriptive statistics were generated to describe (mean, SD, range) all continuous predictors and outcomes of interest, including RTB and RT temperature, temperature difference (RT - RTB), calf weight, ambient temperature during the data-collection period, and milk and water temperature. Strong outliers (defined as $>3$ interquartile ranges from the first and third quartile) were removed from data set as described by Tukey (1977). A Pearson correlation coefficient, a CCC, and associated plots were generated for the association between RT and RTB temperature (STATA ver. 14). The difference in temperature measurement (dependent variable) between the RT and RTB (explanatory variable) was explored using a mixed effects linear regression model with repeated measures on calf. The final main effects model included device, breed, and week. Interactions were explored with the main predictor of interest (device $\times$ breed and device $\times$ week). Both interactions were significant and a stratified analysis was performed. Final significance was determined at $P<0.05$.

Finally, diagnostic test characteristics [sensitivity $(\mathbf{S e})$, specificity $(\mathbf{S p})$, positive predictive value (PPV), negative predictive value, and accuracy (Ac)] of using a single unadjusted RTB measurement to diagnose pyrexia in a calf $\left(\mathrm{RT} \geq 39.5^{\circ} \mathrm{C}\right)$ were calculated using generalized estimating equations, accounting for repeated temperature measures, with calculations performed as described by Dohoo et al. (2009). True prevalence and apparent prevalence of fever, plus a kappa statistic to measure agreement between RTB and RT, were also calculated (Dohoo et al., 2009). The referent test was defined as the RT temperature measurement.

Because the diagnostic test characteristics for using an unadjusted single RTB measurement to diagnose a fever were poor, additional secondary analyses were conducted to recalculate the diagnostic test characteristics. This was done after adjusting the RTB temperature measures, using both the in vitro and in vivo model adjustments, and evaluating different RTB cut-points, ranging from 37.5 to $39.5^{\circ} \mathrm{C}$ in $0.25^{\circ} \mathrm{C}$ increments, to declare a fever present. For the latter approach, the Se, Sp, and Ac for each RTB cut-point were calculated and a receiver operator characteristic analysis was performed to identify the RTB temperature cut-point that maximized both Se and Sp to detect a pyrexic calf (STATA ver. 14).

In vitro data were analyzed for 945 bolus temperature readings over $6 \mathrm{~h}$ (range $=144-176$ readings $/ \mathrm{h})$ and 2 experimental days $(\mathrm{d} 1, \mathrm{n}=452 ; \mathrm{d} 2, \mathrm{n}=493)$. The average WB temperature was $38.6 \pm 1.7^{\circ} \mathrm{C}$ (range $=$ 36.0-42.0) and the average RTB temperature was 38.2 $\pm 1.7^{\circ} \mathrm{C}$ (range $=35.0-41.5$ ). Of the variation in the RTB temperature reading, $98.2 \%$ could be explained by the WB temperature $(\mathrm{r}=0.982)$. The $\mathrm{CCC}$ was 0.952 (95\% CI $=0.947,0.957 ; P<0.001)$. The RTB temperature was estimated to be $0.43 \pm 0.08^{\circ} \mathrm{C}$ lower $(95 \% \mathrm{CI}$ $=-0.58,-0.28 ; P<0.0001)$ than WB temperature.

Seven Holstein and 3 Crossbred heifer calves were enrolled in the in vivo study and represented 235 and 84 temperature measurement observations, respectively. No calves were treated for clinical disease during the study period (1 to 11 wk of age); 319 RT measurements had a corresponding RTB measurement (within \pm 10 min). Week 11 consisted of only 7 observations, and exploratory data analysis revealed 9 strong outliers in all remaining weeks (Tukey, 1977). These 16 observations were removed, leaving 303 matched observations for the final analysis. Removed observations were equally distributed across week and calf. Mean $( \pm \mathrm{SD}) \mathrm{RT}$ and RTB measurements over the study were $38.9 \pm 0.32$ and $38.6 \pm 0.43^{\circ} \mathrm{C}$, respectively. The Pearson correlation coefficient for the relationship between RT and RTB temperature measurements was 0.40 ; the CCC for this relationship was $0.29(95 \% \mathrm{CI}=0.21,0.36 ; P<$ 0.0001).

The multivariable model estimated that RTB temperature was $0.33 \pm 0.06^{\circ} \mathrm{C}(95 \% \mathrm{CI}=-0.44,-0.21$; $P<0.0001)$ lower than the RT (Table 1). After stratifying by breed, the difference between RT and RTB temperature measurements was significant in Holstein calves $\left(-0.30 \pm 0.07^{\circ} \mathrm{C} ; P=0.004\right)$, but this was not true for Crossbred calves $\left(-0.04 \pm 0.11^{\circ} \mathrm{C} ; P=0.74\right)$. After stratifying by week, we found that during all study weeks but wk $5\left(-0.09 \pm 0.07^{\circ} \mathrm{C} ; P=0.23\right)$ the RTB significantly underestimated the RT temperature measurement. Ingestion of a water or milk meal was not associated with temperature readings.

The prevalence of pyrexia $\left(\mathrm{RT} \geq 39.5^{\circ} \mathrm{C}\right)$ measurements in this study population was $4.6 \%$ (14/303; Table 2). The following diagnostic test characteristics for RTB are reported as proportions (95\% CI). Without adjustment, the crude Se and PPV of the RTB to 
Table 1. Final multivariable linear regression model describing the relationship between rumen bolus and rectal temperature measures in calves between 1 to 9 wk of age

\begin{tabular}{|c|c|c|c|c|}
\hline Outcome variable & $\begin{array}{c}\text { Adjusted } \\
\text { mean (SE) }\end{array}$ & $\begin{array}{l}b \text { Coefficient } \\
\text { (SE) }\end{array}$ & $95 \%$ CI & $\begin{array}{l}\text { Type III } \\
P \text {-value }\end{array}$ \\
\hline Intercept & - & $39.04(0.06)$ & - & $<0.0001$ \\
\hline \multicolumn{5}{|l|}{ Device } \\
\hline Bolus & $38.74(0.03)$ & $-0.33(0.06)$ & \multirow[t]{2}{*}{$(-0.44,-0.21)$} & \multirow[t]{2}{*}{$<0.0001$} \\
\hline Rectal & $38.96(0.03)$ & Referent & & \\
\hline \multicolumn{5}{|l|}{ Breed } \\
\hline Crossbred & $38.92(0.04)$ & $-0.031(0.05)$ & \multirow{2}{*}{$(-0.13,0.07)$} & \multirow[t]{2}{*}{0.013} \\
\hline Holstein & $38.77(0.24)$ & Referent & & \\
\hline \multicolumn{5}{|l|}{ Time } \\
\hline wk 1 & $38.69(0.04)$ & $-0.12(0.08)$ & $(-0.27,0.03)$ & \multirow[t]{5}{*}{0.0002} \\
\hline wk 3 & $38.75(0.04)$ & $-0.13(0.08)$ & $(-0.28,0.02)$ & \\
\hline wk 5 & $38.86(0.04)$ & $-0.019(0.09)$ & $(-0.19,0.15)$ & \\
\hline wk 7 & $38.95(0.06)$ & $-0.066(0.07)$ & $(-0.21,0.07)$ & \\
\hline wk 9 & $38.94(0.05)$ & Referent & & \\
\hline \multicolumn{5}{|c|}{ Device $\times$ breed interaction } \\
\hline Bolus $\times$ crossbred & - & $0.36(0.05)$ & $(0.27,0.45)$ & \multirow[t]{3}{*}{$<0.0001$} \\
\hline Bolus $\times$ Holstein & - & Referent & & \\
\hline Rectal $\times$ breed & - & Referent & & \\
\hline \multicolumn{5}{|c|}{ Device $\times$ week interaction } \\
\hline \multicolumn{5}{|c|}{ Bolus $\times$ week } \\
\hline wk 1 & - & $-0.28(0.07)$ & $(-0.42,-0.14)$ & \multirow[t]{6}{*}{$<0.0001$} \\
\hline wk 3 & - & $-0.15(0.07)$ & $(-0.28,-0.01)$ & \\
\hline wk 5 & - & $0.13(0.08)$ & $(-0.04,0.29)$ & \\
\hline wk 7 & - & $-0.04(0.07)$ & $(-0.18,0.09)$ & \\
\hline wk 9 & - & Referent & & \\
\hline Rectal $\times$ week & - & Referent & & \\
\hline
\end{tabular}

predict fever was $0.14(0.03,0.48)$, and $0.25(0.13,0.43)$ respectively. After the RTB temperature adjustment the Se, and PPV of the RTB was $0.29(0.07,0.67)$ and $0.17(0.09,0.27)$ respectively. Results of other adjustments and test characteristics are reported in Table 2.

Results of our study suggest that the Bella Ag RTB measure of temperature is a good predictor of a known temperature in an in vitro (water bath) model. The 2 measures were highly correlated, with RTB tempera- ture estimated to be $0.43 \pm 0.08^{\circ} \mathrm{C}$ lower than the $\mathrm{WB}$ temperature. It is difficult to compare the results of the current study to the results of others, given that different temperature sensing devices are not necessarily directly comparable. One possible explanation for why the RTB underestimated the WB temperature by $0.43^{\circ} \mathrm{C}$ in the current study could be a systematic bias (error) in the calibration of the bolus device. Another explanation could be compounded imprecision of the

Table 2. Test characteristics of the rumen temperature bolus (RTB) to detect a fever (rectal temperature $\geq 39.5^{\circ} \mathrm{C}$; rectal temperature $=$ gold standard); reported as proportion and $95 \% \mathrm{CI}$

\begin{tabular}{lccc}
\hline Test characteristic & Unadjusted $^{1}$ & Model adjusted $^{2}$ & \begin{tabular}{c} 
Optimal RTB $_{\text {cut-point }^{3}}$ \\
\hline True prevalence
\end{tabular} Apparent prevalence \\
Sensitivity & $0.05(0.02,0.07)$ & $0.05(0.02,0.07)$ & $0.05(0.02,0.07)$ \\
Specificity & $0.14(0.01,0.04)$ & $0.08(0.05,0.11)$ & $0.49(0.44,0.55)$ \\
Positive predictive value & $0.98(0.94,0.99)$ & $0.29(0.07,0.67)$ & $0.71(0.42,0.89)$ \\
Negative predictive value & $0.25(0.13,0.43)$ & $0.93(0.82,0.98)$ & $0.52(0.34,0.69)$ \\
Accuracy & $0.96(0.90,0.97)$ & $0.96(0.09,0.27)$ & $0.07(0.02,0.17)$ \\
Kappa & $0.94(0.89,0.97)$ & $0.90(0.81,0.94)$ & $0.97(0.93,0.99)$ \\
& $0.15(0.11,0.19)$ & $0.16(0.12,0.20)$ & $0.53(0.36,0.69)$ \\
\hline
\end{tabular}

${ }^{1}$ Unadjusted $=$ unadjusted RTB temperature measures.

${ }^{2}$ Adjusted $=$ adjusted RTB temperature measures $($ Holstein $=$ bolus temp +0.3 ; Crossbred $=$ bolus temp + 0.04) using the correction factor estimated from the final breed stratified multivariable regression model.

${ }^{3}$ Optimal RTB cut-point $=$ RTB fever defined as a RTB temperature $\geq 38.75^{\circ} \mathrm{C}$ using the temperature cut-point that maximizes sensitivity and specificity to detect a rectal temperature $\geq 39.5^{\circ} \mathrm{C}$ from the receiver operator characteristic analysis. 
bolus and the thermometer ( $\mathrm{Ac}$ of $\pm 0.5^{\circ} \mathrm{C}$ ) used to measure the water bath temperature. The liquid-inglass thermometer was validated before use, but the large accuracy range could result in the bolus appearing to perform worse than it actually did.

In the in vivo study a weaker relationship existed between the RT and RTB in calves $(\mathrm{CCC}=0.29)$ as compared with the work of others studying adult cattle (Bewley et al., 2008a; Rose-Dye et al., 2011; Timsit et al., 2011). However, previous studies tested different devices and were performed in older animals, making it difficult to compare across studies. The RTB underestimated the rectal temperature of calves by approximately $0.33 \pm 0.06^{\circ} \mathrm{C}$. In adult animals, the rumen can be anywhere from 0.45 to $2^{\circ} \mathrm{C}$ (Dale et al., 1954; Bewley et al., 2008a; Timsit et al., 2011) higher than RT due to heat generating fermentation in the rumen. Conversely, Rose-Dye et al. (2011) found that beef steers aged 6 to 8 mo have a slightly higher RT than rumen temperature $\left(0.13^{\circ} \mathrm{C}\right)$, in agreement with our results. Sparse data at wk 11 prevented us from concluding about the relationship after $9 \mathrm{wk}$ of age in this study population. Additionally, for the current study we chose to use a simple digital rectal thermometer, typical of what would be used under field conditions by producers or veterinarians. However, this instrument may have had different results compared with a more precise measurement instrument.

We found that the difference between RT and RTB temperature was not significantly different in crossbred calves as compared with Holstein calves. Liang et al. (2013) found that crossbred lactating dairy cattle have a lower reticuloruminal temperature as compared with purebred Holsteins. The interaction observed between device temperature measurement and week is difficult to explain, but may be in part due to a decreased number of RTB measurements recorded on wk 5 . We had issues with the system reading the bolus signals during some weeks. This is important to note, as reliability is an important factor affecting the utility of a heath management technology, potentially affecting the ability of the system to find sick animals in a timely manner.

Ingestion of water or milk did not cause an important change in RTB temperature measurement or an important change in the relationship (difference) between RTB and RT measures. Water ingestion has been shown to affect rumen temperature in adult cattle (Bewley et al., 2008b), but calves drink very little water (Kertz et al., 1984); thus, bolus temperature fluctuations due to water intake may not be a problem in preweaned animals. Additionally, the milk (average $=38.1^{\circ} \mathrm{C}$ ) meal was not associated with a difference in temperature measures during the hour immediately after ingestion, which is plausible as milk is typically fed at calf body temperature.

The prevalence of pyrexia measures in our study population of calves was low [5\% (14/303) of measurements; $5 / 10$ calves had a least 1 pyrexic event]. Despite adjustment, the RTB had a low sensitivity to detect pyrexia in calves with an increased rectal temperature. This will be problematic if individual RTB measurements (either crude, model-adjusted, or cut-point adjusted) are to be used as a disease-screening test on farms, as it will result in many calves with increased rectal temperatures being missed (false negatives). The predictive power of individual RTB measure to detect a fever was also quite low, which is undesirable for a screening test. However, infectious disease often results in prolonged increased temperatures; therefore, it is conceivable that a calf with a prolonged increase in rectal temperature could be identified by this system with repeated RTB measures reported over an extended period of time. This hypothesis requires further investigation.

The current pilot studies provide some very useful preliminary information regarding the ability of the Bella Ag Cattle Temperature System to accurately measure temperature using an in vitro model. Likewise, this is the first study we are aware of to describe the relationship between RT and RTB temperature measures in growing dairy calves. More research is needed to investigate if evaluation of automated RTB temperature measures collected repeatedly over time may have more utility to detect pyrexic calves under field conditions.

\section{ACKNOWLEDGMENTS}

This study was funded in part by Bella Ag LLC (Loveland, CO). Salary support for Whitney Knauer was provided by USDA (Washington, DC) grant \#2012-38420-30221.

\section{REFERENCES}

Bewley, J. M., M. E. Einstein, M. W. Grott, and M. M. Schutz. 2008a. Comparison of reticular and rectal core body temperatures in lactating dairy cows. J. Dairy Sci. 91:4661-4672.

Bewley, J. M., M. W. Grott, M. E. Einstein, and M. M. Schutz. 2008b. Impact of intake water temperatures on reticular temperatures of lactating dairy cows. J. Dairy Sci. 91:3880-3887.

Dale, H. E., R. E. Stewart, and S. Brody. 1954. Rumen temperature. 1. Temperature gradients during feeding and fasting. Cornell Vet. 44:368-374.

Dohoo, I., W. Martin, and H. Stryhn. 2009. Veterinary Epidemiologic Research. VER Inc., Charlottetown, Prince Edward Island, Canada.

Kertz, A. F., L. F. Reutzel, and J. H. Mahoney. 1984. Ad libitum water intake by neonatal calves and its relationship to calf starter intake, weight gain, feces score, and season. J. Dairy Sci. 67:2964-2969. 
Liang, D., C. L. Wood, K. J. McQuerry, D. L. Ray, F. D. Clark, and J. M. Bewley. 2011. Influence of breed, milk production, season, and ambient temperature on dairy cow reticulorumen temperature. J. Dairy Sci. 96:5072-5081.

McGuirk, S. M. 2008. Disease management of dairy calves and heifers. Vet. Clin. North Am. Food Anim. Pract. 24:139-153.

Rose-Dye, T. K., L. O. Burciaga-Robles, C. R. Krehbiel, D. L. Step, R. W. Fulton, A. W. Confer, and C. J. Richards. 2011. Rumen temperature change monitored with remote rumen temperature boluses after challenges with bovine viral diarrhea virus and Mannheimia haemolytica. J. Anim. Sci. 89:1193-1200.

Smith, B. 2009. Manifestations and management of disease in neonatal ruminants. Page 276 in Large Animal Internal Medicine. 4th ed. Mosby Elsevier, St. Louis, MO.
Timsit, E., S. Assie, R. Quiniou, H. Seegers, and N. Bareille. 2011. Early detection of bovine respiratory disease in young bulls using reticulo-rumen temperature boluses. Vet. J. 190:136-142.

Tukey, J. W. 1977. Exploratory Data Analysis. Addison-Wesley, Reading, MA.

Vickers, L. A., O. Burfeind, M. A. G. von Keyserlingk, D. M. Veira, D. M. Weary, and W. Heuwieser. 2010. Technical note: Comparison of rectal and vaginal temperatures in lactating dairy cows. J. Dairy Sci. 93:5246-5251. 